\title{
Evaluation of Physical Parameters of Novel Licorice Varnish Versus Fluoride and Combination Varnish: An In-Vitro Study
}

\author{
Roopali Sankeshwari ${ }^{1}$, Anil Ankola ${ }^{1}$, Kishore Bhat ${ }^{2}$, Udaya Bolmal ${ }^{3}$, Malleswara Rao ${ }^{2}$
}

${ }^{1}$ Department of Public Health Dentistry, KLE Vishwanath Katti Institute of Dental Sciences, KLE Academy of Higher Education and Research, Belgaum, Karnataka, India, ${ }^{2}$ KLE Dr Prabhakar Kore Basic Science Research Centre, KLE Academy of Higher Education and Research, Belgaum, Karnataka, India, ${ }^{3}$ KLE College of Pharmacy, KLE Academy of Higher Education and Research, Belgaum, Karnataka, India.

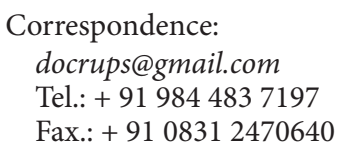

Received: 22 May 2018

Accepted: 3 October 2018

Key words: Dental Varnish - Early Childhood Caries - Licorice - Prevention of Tooth Decay - Streptococcus Mutans.

\begin{abstract}
Objectives. The aim of this study was to evaluate the physical properties of locally prepared Licorice varnish (LV), commercially available Fluoride varnish (FV) and a Combination of both Varnishes (CV). Material and Methods. LV was prepared using authenticated licorice roots. Commercially available FV (Bifluorid 12) was used as a positive control and CV was prepared in six different concentrations of both varnishes. Conventional antibacterial activity assessment, employing disc diffusion and broth dilution methods, was inconclusive. Therefore a novel assessment method was used, whereby the varnish was directly added to a mixture of Brain Heart Infusion broth with Streptococcus mutans and incubated. Physical parameters such as $\mathrm{pH}$, rate of evaporation, viscosity, film forming ability, and cost incurred for preparation were assessed and compared. Results. FV, LV and CV (except the combination of LV 80\% + FV 20\%) showed antibacterial activity against Streptococcus mutans. All three varnishes formed films on the tooth surface as confirmed by Scanning Electron Microscopy. Mean $\mathrm{pH}$ was in the range of 4-4.5, viscosity 48-52 centipoise (cP), rate of evaporation was $150-160$ seconds. They were comparable to each other in the physical parameters tested, except for the shelf life of LV. Conclusion. All three varnishes showed antibacterial activity against Streptococcus mutans which was established using an innovative method of antibacterial activity assessment. LV was most economical of all but had a shorter shelf life. The results of this study need to be evaluated through an in vivo study.
\end{abstract}

\section{Introduction}

Dental caries is the most common chronic infectious disease in childhood (1). Early Childhood Caries (ECC) is a devastating form of dental disease affecting the youngest members of society. Children's quality of life can be seriously affected by severe caries because of pain and discomfort which could lead to disfigurement, acute and chronic infections, and altered eating and sleeping habits, as well as the risk of hospitalisation, high treatment costs, and the loss of school days, with the consequent diminished ability to learn (2). The knowledge about dental caries has increased, but dentists worldwide are struggling to prevent ECC. Communitybased preventive programs have to be developed and implemented urgently to achieve the World Health Organization (WHO) goals, and to improve oral health, health in general and the quality of life in particular (3).

The foremost of all caries preventive tools is Fluoride which can favourably al- 
ter demineralisation and remineralisation processes, thus preventing caries (4). Longlasting pharmaceutical formulations in the form of varnishes have been developed for the prevention of dental caries (5).Varnishes are easy to apply, have a high concentration of fluoride, and can be applied in a moist environment, and thus can be considered as the best preventive tool against ECC (6). The remineralising capacity and antibacterial activity of Fluoride against Streptococcus mutans have been reported and time tested, however, the cost and manpower required for fluoride varnish application necessitate the search for other alternative preventive tools. The gap in the knowledge base in this regard remains a topic for exploration, as in the present study.

Recently, there has been an increasing interest in herbal dentistry to overcome drawbacks of modern medicine such as the development of resistance to antibiotics, and side effects such as vomiting, diarrhoea, alteration of taste sensations, etc. (7). There has been growing interest in biologically active compounds, derived from natural products, which may have potential therapeutic uses in dentistry (8). Ayurveda has a wide range of medicinal plants which have been used to alleviate human suffering and promote general health and well being. Among the various medicinal plants used, Licorice - Glycyrrhizaglabra is one such plant. Licorice, known as the "Grandfather of Herbs," has been used by various cultures and is time tested. It is 50 times sweeter than sucrose, has been successfully used to relieve sore throat and gastric problems, and enhance memory in children. It is easily available, inexpensive, approved by the US FDA as GRAS (generally regarded as safe as per 21 CFR section, 21CFR 184-1408) and $\mathrm{LD}_{50}$ of Glycyrrhizin is $1.94 \mathrm{~g} / \mathrm{kg}$ subcutaneously (9) indicative of a good safety profile.

Isolated use of fluoride has proved to be insufficient to prevent progressive mineral loss and consequent lesion formation in children at high risk for caries development (10). Hence the combination of fluoride with licorice varnish was undertaken with the idea that the combination may control plaque formation with reduced acidogenicity, and may also help in remineralization of initial lesions.

Thus the objective of the study was to compare the physical properties of all three varnishes. We also compared the cost incurred for preparation of the varnish.

\section{Materials and Methods}

The present study was carried out from Jan 2016 to April 2016 at the Dr. Prabhakar Kore Basic Science Research Centre, Belagavi. Ethical clearance was obtained from the Institutional Ethics Committee. Authenticated Licorice roots were used to prepare Licorice extract using the cold maceration method. The extract was filtered using a muslin cloth and Whatman No.1 filter paper. The filtrate was concentrated using an IKA Rotary evaporator at $40^{\circ} \mathrm{C}$, and the resultant residue was kept in a refrigerator until further use. The extract obtained was assessed for its antimicrobial activity against Streptococcus mutans ATCC 25175 (procured from PGI Chandigarh) using the broth dilution method.

\section{Licorice Varnish (LV)}

The Faculty of Pharmacy guided the preparation of Licorice Varnish. All ingredients of IP (Indian Pharmacopeia) grade, were used for preparing the varnish (Table 1). A manual of operations was prepared, and the Good Laboratory Practices (GLP) guidelines were followed for the varnish preparation. LV was prepared by the addition of ethyl acetate to licorice extract in a sterile glass container. The extract was dissolved by keeping a glass container in a bath sonicator for 30 minutes. When the extract was completely dissolved, 
Table 1. Ingredients Used for Preparing Licorice Varnish Along with Their Functions

\begin{tabular}{lll}
\hline Ingredient & Function & Manufacturer \\
\hline Iso amyl propionate purchased from Sigma & Plasticizer & Sigma Aldrich, SAPC \\
Ethyl acetate & Solvent & Sigma Aldrich, SAPC \\
Collodion solution, gift sample from Sigma & Lacquer & Omatek Laboratories,Indore. \\
Fumed silica-Gift sample, Aerosil 200 & Thickening agent & Pharma from Evonik Industries,Germany \\
Licorice extract & Antimicrobial activity & Indigenously prepared \\
\hline
\end{tabular}

Collodion solution, along with Iso Amyl Propionate was added. It was centrifuged again and fumed silica was added to this mixture. All the contents were centrifuged for 30 seconds and the mixture was transferred to an amber colored sterile bottle and labeled.

\section{Fluoride Varnish (FV)}

Commercially available Bifluorid12 varnish (VOCO Company, Germany. Lot no.1523310) was used as a positive control.

\section{Combination Varnish (CV)}

This was initially prepared by mixing $80 \% \mathrm{LV}$ with $20 \%$ FV but when it failed, other combinations were tested. Combination varnish was prepared by mixing various concentrations of licorice varnish and fluoride varnish as described below: $50 \% \mathrm{LV}+50 \% \mathrm{FV} ; 60 \%$ $\mathrm{LV}+40 \% \mathrm{FV} ; 75 \% \mathrm{LV}+25 \% \mathrm{FV} ; 60 \% \mathrm{FV}+$ $40 \% \mathrm{LV} ; 75 \% \mathrm{FV}+25 \% \mathrm{LV}$. All the three varnishes were assessed for their antimicrobial activity and physical parameters.

Antimicrobial activity - The antimicrobial susceptibility test was performed according to the Agar diffusion method. Streptococcus mutans ATCC 25175 was cultivated in Brain Heart Infusion (BHI) broth, and it was transferred after 18 hours to BHI agar containing $5 \%$ sucrose.

Disc diffusion method - The direct colony suspension method for the preparation of inoculums was followed. The inocula of Streptococcus mutans was prepared by col- lecting 3-4 colonies grown on agar after 24 hours and the number of microorganisms was calculated based on the standard turbidity of 0.5 McFarland, corresponding to $1.0 \times 10^{8}$ colony forming units $/ \mathrm{ml}$. All the three varnishes, FV, LV and $\mathrm{CV}$, were diluted to concentrations ranging from $100 \%$, $50 \%, 25 \%, 12.5 \%$ and $6.25 \%$ with the help of distilled water. Twenty micro liters of the respective varnishes were transferred onto sterile filter papers $(6.4 \mathrm{~mm}$ diameter $)$ and placed on the agar plate. The plates were then incubated at $37^{\circ} \mathrm{C}$ for 48 hours anaerobically. The varnishes, being alcoholic mixtures, evaporated and did not diffuse through the agar plates (Figure 1).

Broth dilution method - The broth dilution method was attempted next. As a

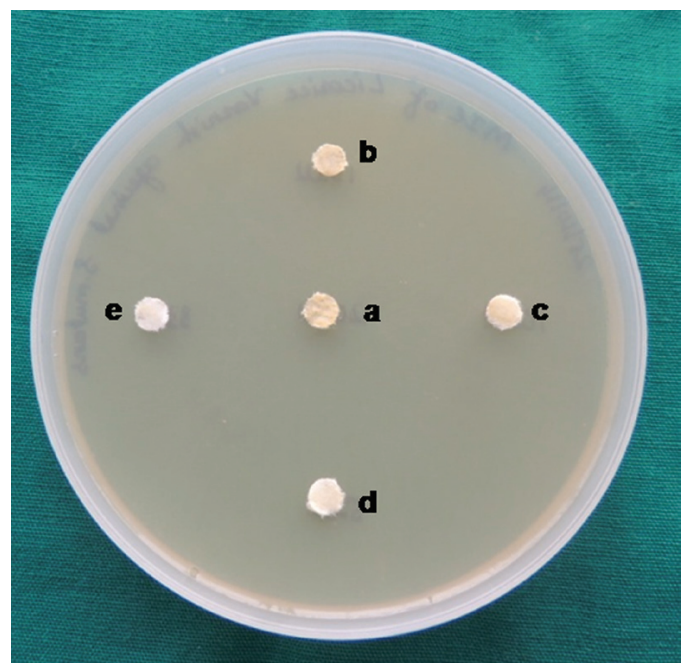

Figure 1. Disk diffusion method showing failure of varnishes (various dilutions: $a=100 \%, b=50 \%$, $c=25 \%, d=12.5 \%$ and $e=6.25 \%)$ to diffuse through agar medium. 
procedural step, varnish was added to BHI broth, but as soon as the varnish was mixed with BHI broth a precipitate formed immediately annulling the chance of any further investigation. Since varnish is made up of resins, as soon as it was mixed with broth, a precipitate occurred (Figure 2). Since the result was inconclusive, this method was also discarded. The routine tests employed for testing the MIC of varnish failed and, hence there was a need to develop a novel method to assess the MIC of varnish.

Novel method - In this method, $0.5 \mathrm{ml}$ of varnish was added directly to a mixture of 0.5 $\mathrm{ml}$ of BHI broth and Streptococcus mutans. One loop of this mixture was then spread over agar gel and incubated for 48 hours. A similar procedure was repeated with $\mathrm{LV}$ and $\mathrm{CV}$ and the results obtained are shown in Figure 3. As can be seen clearly, CV in a ratio of $80 \%$ LV and $20 \% \mathrm{FV}$, failed to show antimicrobial activity. All three varnishes were tested for physical properties by the principal investigator who was trained at KLE Dr. Prabhakar Kore Basic Science Research Centre.

Color matching - The freshly prepared LV was compared with the shade guide and the shade number was noted, along with the date of preparation. This helped us to assess

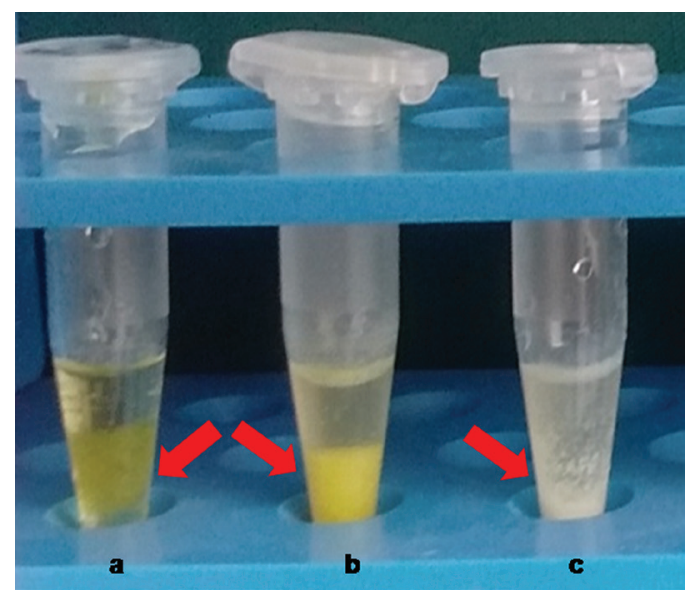

Figure 2. The broth dilution method showing the formation of precipitate upon addition of varnishes to Brain Heart Infusion broth: a=Licorice varnish; $b=$ Fluoride varnish; $c=$ Combination varnish the shelf life of the varnish. When performing the color matching, the investigator was wearing a vision aid, clear spectacles which are normally worn every day. The test area had the artificial natural daylight fluorescent illumination. The specimen was held at a distance of $25 \mathrm{cms}$ and was observed at perpendicularly. Color matching was done between the shade guide and the specimen. The intra observer agreement was calculated as the mean value of the highest percentage of identical scores for 6 specimen of the same shade, performed twice at an interval of one week: 1) Rate of evaporation - A sterile glass slide was taken and its weight was noted down. One hundred micro liters of varnish was then dispensed on it and evenly distributed, and kept on a digital weighing scale. A stop-watch was used to assess the time taken for the slide to return to its original weight. Viscosity was assessed using a CAP 2000 + Viscometer, Brookfield. Two ml of the varnish was placed on the viscometer plate and the test was run according to the manufacturer's instructions and values noted. 2) Film forming ability - Human Tooth samples of $3 \mathrm{~mm}$ thickness were obtained using hard tissue microtome. Fifty micro liters of the respective varnishes were applied us-

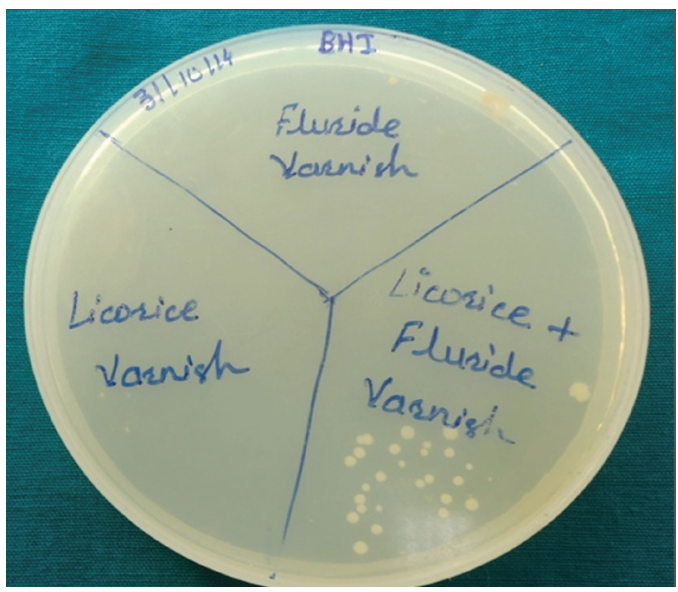

Figure 3. New method for assessing the MIC of all three varnishes. Combination varnish ( $80 \%$ Licorice varnish and $20 \%$ Fluoride varnish) failed to show antibacterial activity. 
ing the applicator tip. After the samples were completely dried, they were observed under a Scanning Electron Microscope (SEM). The morphology of the formed films on the tooth surface was studied using a JOEL Scanning Electron Microscope, Model JSM- 6360LV, operating in $15 \mathrm{kV}$ acceleration voltage. 3) The safety of the LV was assessed by comparing the lethal doses of all the ingredients used with the actual concentration used for preparing the varnish (11-13).

\section{Statistical Analysis}

The data was analyzed using SPSS software version 20 (SPSS Inc Chicago, USA). The level of significance was set at 0.05 . Intra examiner reproducibility was assessed using Cohen's Kappa for color matching. Triplicate values were used to determine the mean value for rate of evaporation and viscosity of the varnishes.

\section{Results}

Intra examiner Cohen's Kappa $(\mathrm{k})$ for color matching was 0.86 , confirming good reproducibility. The licorice extract, along with $\mathrm{LV}$ and FV, showed antimicrobial activity (Table 2). CV showed antimicrobial activity in all the tested permutations except $80 \%$ LV and 20\% FV (Figure 4). All the combination of varnishes, that is $(60 \% \mathrm{FV}+40 \%$ $\mathrm{LV}),(40 \% \mathrm{FV}+60 \% \mathrm{LV}),(25 \% \mathrm{FV}+75 \% \mathrm{LV})$, $(75 \% \mathrm{FV}+25 \% \mathrm{LV})$ and $(50 \% \mathrm{FV}+50 \% \mathrm{LV})$, were equally effective with regard to antibacterial activity. The combination varnish in the concentration of $(50 \% \mathrm{FV}+50 \% \mathrm{LV})$ was easier to prepare in terms of time and cost. Hence the physical parameters were assessed using this proportion and the results obtained are shown in Table 3. All the varnishes were acidic in nature.

Table 2. Results of Minimal Inhibitory Concentrations of Licorice Extract and the Three Varnishes Against Streptococcus Mutans

\begin{tabular}{ll}
\hline Test group & Antibacterial activity against Streptococcus mutans \\
\hline Licorice extract & Positive - $2.0 \mathrm{mg} / \mathrm{ml}$ \\
Licorice varnish & Positive \\
Fluoride varnish & Positive \\
\hline Combination varnish & \\
\hline $80 \%$ Licorice Varnish $+20 \%$ Fluoride Varnish & Negative \\
$50 \%$ Licorice Varnish $+50 \%$ Fluoride Varnish & Positive \\
$60 \%$ Licorice Varnish $+40 \%$ Fluoride Varnish & Positive \\
$75 \%$ Licorice Varnish $+25 \%$ Fluoride Varnish & Positive \\
$60 \%$ Fluoride Varnish $+40 \%$ Licorice Varnish & Positive \\
\hline
\end{tabular}

Table 3. Comparison of the Physical Parameters of All Three Varnishes

\begin{tabular}{llll}
\hline Parameters & Fluoride varnish & Licorice varnish & Combination varnish \\
\hline $\begin{array}{l}\text { Rate of evaporation } \\
\text { (second) }\end{array}$ & 150 & 156 & 160 \\
$\mathrm{pH}$ & 4 & 4.5 & 4.5 \\
Viscosity (Pa*s) & 48 & 52 & 49 \\
Shelf life & Stable for 2 years & Shelf life 35 days & Shelf life 2 months \\
Cost & Rs 4500 per bottle* & Rs 700 per bottle; 6-7 times cheaper ${ }^{\dagger}$ & Approximately Rs 2500 per bottle \\
\hline
\end{tabular}

Pa*s=Pascal seconds; "Biflurid 12 Voco product; ' Indigenously prepared; Rs=Indian Rupees. 

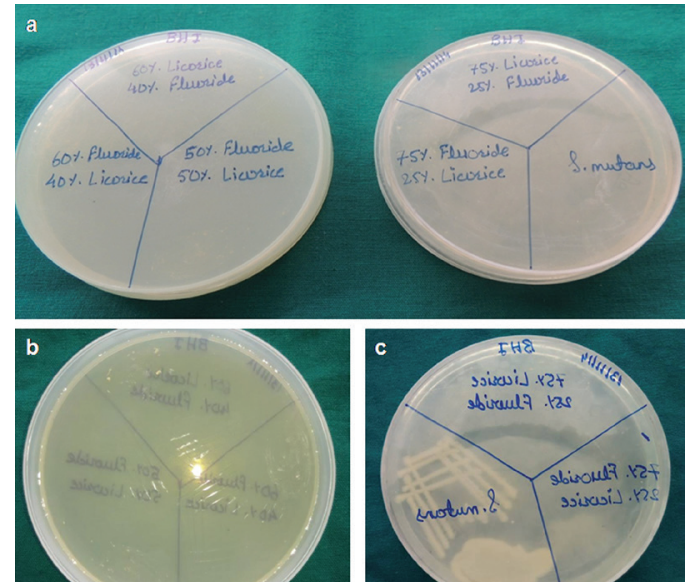

Figure 4: a) The combination varnish showed antimicrobial activity in all the tested permutations; $b$ ) No growth of Streptococcus mutans was seen in any of the combination varnishes; c) Streptococcus mutans growth was seen in the control group.

1

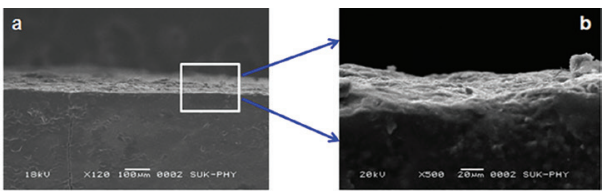

II

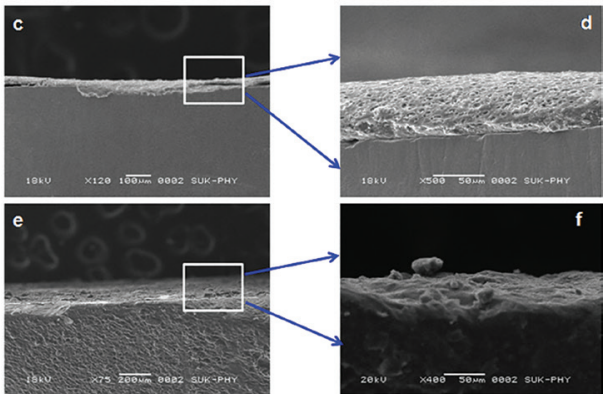

Figure 5. Morphological characterization of films formed on the tooth surface after application of varnishes. SEM images of I=Licorice varnish; II=Fluoride varnish; $I I I=C o m b i n a t i o n$ varnish $(a, c$, e side view; $b$, d, f expansion view).
The safety profile of various components used in preparing LV is presented in Table 4.

Scanning Electron Microscopy (SEM) results - SEM images are presented in Figure 5. The images reveal the uniform film formation of all the three varnishes. The films were in intimate contact with the tooth. However, the compactness of the varnishes differed from one another.

\section{Discussion}

This study describes the development of a novel LV, as well as a new method to assess the MIC of varnish. The dental profession is currently faced with an enormous task of how to manage the huge burden of the consequences of the caries process amongst the world population (14). Providing care for preschool children can be stressful and troublesome (5). Hence, the focus is currently on minimally invasive approaches which can arrest caries progression. Fluoride is the most essential chemical agent used for dental caries prevention, and various topical fluoride interventions have been supporting this, with over six decades of experimental research (15). However, an increased resistance to caries from fluoride has been reported (16).

The present study compared locally prepared LV with FV and their combination. The antimicrobial activity was assessed using a novel method for LV. An extensive literature review showed that there were no

Table 4. Comparison Between the Toxic Values of Varnish Ingredients and the Actual Concentrations Used per Milliliter of the Varnish

\begin{tabular}{lll}
\hline Ingredient & Toxicity profile & Concentration* $^{*}$ \\
\hline Licorice extract & $\begin{array}{l}\text { Animal studies - it does not cause genotoxicity, cytotoxicity or cellular } \\
\text { toxicity. } 1.94 \mathrm{gms} / \mathrm{kg} \mathrm{(29)}\end{array}$ & $8 \mathrm{mg}$ \\
Iso amyl propionate & Approximately $5 \mathrm{ml} / \mathrm{kg} \mathrm{(12)}$ & $0.1 \mathrm{ml}$ \\
Aerosil & $>3160 \mathrm{mg} / \mathrm{kg}$ body weight (Evonik MSDS datasheet) & $10 \mathrm{mg}$ \\
Ethyl acetate & $11.3 \mathrm{~g} / \mathrm{kg}$ body weight (12) & $0.2 \mathrm{ml}$ \\
Collodion solution & $10 \mathrm{mg} / \mathrm{kg} \mathrm{(12)}$ & $0.2 \mathrm{ml}$ \\
\hline
\end{tabular}

"Concentration used per milliliter of licorice varnish. 
reports on licorice varnish and our study seems to be the first one. In the present study, licorice extract was found to have an effective antibacterial activity against Streptococcus mutans, and this result is in concordance with other studies $(17,18)$. Licorice contains alkaloids, flavonoids, saponins like glycyrrhizic acid, glycyrrhizin and stilbenes gancaonin $G$ which have antimicrobial and anti-adherent properties against Streptococcus mutans and thus can help in caries control (19). The minimum inhibitory concentrations (MIC) of licorice varnish provide evidence that, even when the licorice extract was mixed with the other constituents of varnish, the extract was able to sustain its antimicrobial activity. The licorice varnish can be considered as a pragmatic option to prevent dental caries.

Though in vitro studies have made it clear that licorice has good antimicrobial activity against Streptococcus mutans and other organisms, it has not been used in a therapeutic form which is practical and feasible in a field trial involving preschool children. MIC is considered the 'gold standard' for determining the susceptibility of organisms to antimicrobials and is therefore used to judge the performance of all other methods of susceptibility testing (20). Varnishes, being alcoholic mixtures, evaporated and failed to diffuse through the agar plates. Hence, the conventional tests employed for testing MIC of varnish did not give any results, and a new technique which could overcome this problem was needed.

The inability of the varnish to diffuse through agar medium was overcome by the novel method, and the varnish acted directly on Streptococcus mutans, thus demonstrating the antimicrobial potential of the varnish. Antimicrobial testing of propolis varnish has been reported (21) where the authors diluted propolis varnish in an ethanol-water solution at $20 \%$ in a proportion of $1: 1(75 \mathrm{mg} / \mathrm{ml})$ to reduce the viscosity of the varnish. This technique though it provided satisfactory results, actually camouflages the inherent antimicrobial activity of the varnish. Thus this particular technique was not followed in the present study.

When the cost factor was compared, LV proved to be more economical compared to FV. It is about 6-7 times cheaper than FV (Bifluorid 12). A comparison of the three varnishes revealed that licorice and $\mathrm{CV}$ were comparable to FV in most of the parameters assessed. However, when shelf life was assessed, LV had a shorter shelf life. When the rate of evaporation was assessed, it was found to be slightly longer for $\mathrm{LV}$, although the difference was not statistically significant. This could be attributed to the lower viscosity of LV.

Combination varnishes, such as fluoride with chlorhexidine, fluoride with cervitec, and chlorhexidine with xylitol, have been used in dentistry, as the combinations have been shown to increase the suppression period of Streptococcus mutans (22-24). Both Cervitec $\mathrm{F}$ and fluoride varnish performed similarly when their antimicrobial activity against Streptococcus mutans was compared (24). Contrary to this, MI varnish, a newer combination varnish with CPP-ACP and fluoride, was compared against plain fluoride varnish and chlorhexidine varnish, but chlorhexidine showed significantly better results than a combination of CPP-ACP and fluoride varnish for antibacterial activity against Streptococcus mutans (25). On the other hand, Gedalia (26) reported that when Glycyrrhizin (Licorice) was added to the APF solution, fluoride uptake increased and enamel solubility was reduced. To test this hypothesis, a CV was tested in the present study. In the present study, CV prepared by mixing $80 \% \mathrm{LV}$ with $20 \% \mathrm{FV}$ failed to show antimicrobial activity. This may be due to the high concentration of licorice $(80 \%)$ varnish in the $\mathrm{CV}$ which probably antagonized the effect of fluoride varnish present 
in a lower concentration (20\%). Further, the interaction between the active constituents of licorice varnish with the sodium and calcium fluoride present in fluoride varnish may have resulted in the annulling of each other's antimicrobial activity. However, the exact reason why the combination varnish with $80 \%$ LV with $20 \%$ FV failed to show any antimicrobial activity remains unclear. An interaction study between licorice and fluoride varnish is probably needed to find the answer, however it was beyond the scope of the present research. FV has multiple effects such as remineralization of initial enamel lesions and inhibition of Streptococcus mutans. We can predict that when licorice is mixed with $\mathrm{FV}$ it probably enhances the antibacterial activity of FV. The inhibition of plaque biofilm formation is the key to successful control and prevention of dental caries (27). This may indirectly enhance the remineralizing potential of $\mathrm{CV}$ and at a cost much lower than FV. Will CV improve the efficiency of the Gold standard "FV "in preventing ECC? This question needs to be answered in future studies.

As shown by SEM analysis, varnish formulations formed a uniform layer on the tooth structure. FV (Bifluorid 12) contains $5.6 \% \mathrm{~F}$, and both sodium fluoride and calcium fluoride, which could penetrate the tooth surface more effectively (28). Hence, this was used as a positive control in the present study. Both sodium and calcium ions are positively charged ions, and have a high affinity to the fluoride ion. This affinity makes $\mathrm{CaF}$ and $\mathrm{NaF}$ crystals more stable, thus enabling the compact nature of the varnish. However, it has been reported that since Bifluorid 12 has higher viscosity, it formed a thicker layer on the acrylic surface to which Streptococcus mutans adhered easily (29). On the other hand, LV had lower viscosity, and we can speculate that it would penetrate the enamel tags to a greater depth. Whether these properties make any signifi- cant impact on caries progression or biofilm formation needs to be assessed through invivo studies.

\section{Safety Issues}

Licorice has been used by various cultures for thousands of years and many previous studies have shown that it is a safe medicinal herb (30). Ames test using S Typhimurium TA 1535 revealed no genotoxicity; a cytotoxicity study with Promega's CellTiter-Glo Assay, using cell lines of Jurkat HOK68 $\mathrm{CHO}$ and $\mathrm{BHK}$, revealed no cellular toxicity. A single dose acute toxicity test with mice confirmed Glycyrrhiza glabra to be non-toxic (30). All the ingredients used in the present study were of $I P$ (Indian Pharmacopeia) Grade, and GLP (Good Laboratory Practices) guidelines were followed during the preparation of $\mathrm{LV}$, thus ensuring the safety of LV and CV.

Dental caries is a multifactorial disease and many organisms cause this disease. However, in the present study, a single organism was used, that is, Streptococcus mutans. It would be interesting to find out if LV has broad spectrum antibacterial activity in future studies, by assessing its antibacterial activity against other oral pathogens. Nevertheless, such an investigation was beyond the scope of the present study. The shelf life of LV was found to be shorter than FV, and further studies with respect to optimization of methods for preparation of the varnish are required to improve the product.

\section{Conclusion}

LV, FV and CV (except $80 \% \mathrm{LV}+20 \% \mathrm{FV}$ ) showed antimicrobial activity against the standard strain of Streptococcus mutans. The viscosity, rate of evaporation, $\mathrm{pH}$, and film forming ability of all three varnishes were comparable to each other. LV was the most economical of the three but had a shorter 
shelf life. Future studies with in vivo study design are required to confirm these findings.

\section{What is already known on this topic}

ECC is pandemic in prevalence and is amenable to prevention. The Cochrane database recommends the use of fluoride varnish for the prevention of dental caries in young children. However, varnish is an expensive preventive tool, especially for developing countries where the prevalence of the disease is high, and resources to tackle it are limited and hence there is a need to search for an alternative indigenous product. Licorice has been used for various ailments for centuries and has been used in dentistry as a mouthwash and lollipop for its anti caries activity against Streptococcus mutans.

\section{What this study adds}

Although the anti-cariogenic properties of licorice have been suggested for over 30 years, it has not been tested in a dosage form that can be used in public health programs. Hence this study presents the details of licorice varnish its preparation and its comparison with fluoride varnish. A combination varnish may provide more benefits by suppressing the acidogenic bacteria in addition to accelerating the remineralization process of white spot lesions. The present research work also describes a novel way of assessing the MIC of a viscous substance such is "dental varnish".

Acknowledgement: The authors would like to thank Dr. Vinuta Hampiholi, Dr. Sagar Jalihal and Dr. Setu Havanur for their valuable input during proof reading of the manuscript. We are thankful to Dr. Hemanti Bhattacharya for rendering help in MIC procedures.

Authors' contributions: Conception and design: RS and AA; Acquisition, analysis and interpretation of data: RS, KB and UB; Drafting the article: RS and MR; Revising it critically for important intellectual content: $\mathrm{KB}, \mathrm{UB}$ and MR; Approved final version of the manuscript: RS, AA, KB, UB and MR.

Conflicts of interests: The authors declare that they have no conflict of interest.

\section{References}

1. Blanaid Daly, Paul Batchelor ET and RW. Essential Dental Public Health. 1sted. London: Oxford University Press; 2002. p. 8.

2. Petersen PE, Estupinan-Day S, Ndiaye C. WHO's action for continuous improvement in oral health. Bull World Health Organ. 2005;83(9):642.

3. Sacic L, Markovic N, Arslanagic Muratbegovic A, Zukanovic A, Kobaslija S. The prevalence and se- verity of early childhood caries in preschool children in the Federation of Bosnia and Herzegovina. Acta Med Acad. 2016;45(1):19-25.

4. Rošin-Grget K. The cariostatic mechanisms of fluoride. Acta Med Acad. 2013;42(2):179-88

5. Duangthip D, Jiang $\mathrm{M}$, Chu $\mathrm{CH}$, Lo EC. Nonsurgical treatment of dentin caries in preschool children - systematic review. BMC Oral Health. 2015;15(1):44.

6. Marinho VCC, Worthington HV, Walsh T, Clarkson JE. Fluoride varnishes for preventing dental caries in children and adolescents. Cochrane database Syst Rev. 2013;7:CD002279.

7. Freires IA, Rosalen PL. How Natural Product Research has Contributed to Oral Care Product Development? A Critical View. Pharm Res. 2016;33(6):1311-7.

8. Groppo FC, De Cássia Bergamaschi C, Cogo K, Franz-Montan M, Motta RHL, De Andrade ED. Use of phytotherapy in dentistry. Phytotherapy Research. 2008;22(8):993-8.

9. Pandey G. Dravyaguna Vijnana: Materia MedicaVegetable Drugs. Vol 2. Varanasi: Chaukhambha Krishnadas Academy; 2004.

10. Ullsfoss BN, Øgaard B, Arends J, Ruben J, Rölla G, Afseth J. Effect of a combined chlorhexidine and $\mathrm{NaF}$ mouthrinse: an in vivo human caries model study. Eur J Oral Sci. 1994;102(2):109-12.

11. Evonik Resource efficiency Gmbh| Product information AEROSIL ${ }^{\star} 200$ Pharma [updated Aug 2012] [cited 2016 Jan 4]. Available from https:// products-re.evonik.com/www2/uploads/.../ AEROSIL-200-Pharma-EN.pdf.

12. Leonard BJ. Toxicological Aspects of Food Safety: Proceedings of the European Society of Toxicology Meeting held in Copenhagen, June 19-22, 1977. Berlin: Springer-Verlag; 1978.

13. World Health Organization. Evaluation of certain food additives (Seventyninth report of the Joint FAO/WHO Expert Committee on Food Additives). WHO Technical Report Series, No. 990. Geneva: World Health Organization; 2014.

14. Frencken JE, Peters MC, Manton DJ, Leal SC, Gordan VV, Eden E. Minimal intervention dentistry for managing dental caries - A review: Report of a FDI task group. Int Dent J. 2012;62(5):223-43.

15. Lopes RM, Domingues GG, Junqueira SR, Araujo ME, Frias AC. Conditional factors for untreated caries in 12-year-old children in the city of São Paulo. Public Health. 2013;27(4):376-81.

16. Sheiham A, Sabbah W. Using universal patterns of caries for planning and evaluating dental care. Caries Res. 2010;44(2):141-50. 
17. Jain E, Pandey RK, Khanna R. Liquorice root extracts as potent cariostatic agents in pediatric practice. J Indian Soc Pedod Prev Dent. 2013;31(3):146-52.

18. Gupta VK, Fatima A, Faridi U, Negi AS, Shanker $\mathrm{K}$, Kumar JK, et al. Antimicrobial potential of Glycyrrhiza glabra roots. J Ethnopharmacol. 2008;116(2):377-80.

19. Messier C, Epifano F, Genovese S, Grenier D. Licorice and its potential beneficial effects in common oro-dental diseases. Oral Dis. 2012;18(1):32-9.

20. Andrews JM, Andrews JM. Determination of minimum inhibitory concentrations. J Antimicrob Chemother. 2001;48(Suppl 1):S5-16.

21. De Luca MP, Franca JR, Macedo FAFF, Grenho L, Cortes ME, Faraco AAG, et al. Propolis varnish: antimicrobial properties against cariogenic bacteria, cytotoxicity, and sustained-release profile. Biomed Res Int. 2014;2014:348647.

22. Baygin O, Tuzuner T, Kusgoz A, Senel AC, Tanriver M, Arslan I. Antibacterial effects of fluoride varnish compared with chlorhexidine plus fluoride in disabled children. Oral Health Prev Dent. 2014;12(4):373-82.

23. Paula VAC, Modesto A, Santos KRN, Gleiser R. Antimicrobial effects of the combination of chlorhexidine and xylitol. Br Dent J. 2010;209(12):E19.

24. Lipták L, Bársony N, Twetman S, Madléna M. The effect of a chlorhexidine-fluoride varnish on mutans streptococci counts and laser fluorescence readings in occlusal fissures of permanent teeth: A split-mouth study. Quintessence Int. 2016;47(9):767-73.

25. Patel PM, Hugar SM, Halikerimath S, Badakar CM, Gokhale NS, Thakkar PJ, et al. Comparison of the effect of fluoride varnish, chlorhexidine varnish and casein phosphopeptide- amorphous calcium phosphate (CPP-ACP) varnish on salivary streptococcus mutans level: A six month clinical study. J Clin Diagnostic Res. 2017;11(8):ZC53-9.

26. Gedalia I, Stabholtz A, Lavie A, Shapira L, Pisanti S, Segal R. The effect of glycyrrhizin on in vitro fluoride uptake by tooth enamel and subsequent demineralization. Clin Prev Dent. 1986;8(2):5-9.

27. Franca JR, De Luca MP, Ribeiro TG, Castilho RO, Moreira AN, Santos VR, et al. Propolis--based chitosan varnish: drug delivery, controlled release and antimicrobial activity against oral pathogen bacteria. BMC Complement Altern Med. 2014;14:478.

28. Bergström EK, Birkhed D, Granlund C, Sköld UM. Approximal caries increment in adolescents in a low caries prevalence area in Sweden after a 3.5-year school-based fluoride varnish programme with Bifluorid 12 and Duraphat. Community Dent Oral Epidemiol. 2014;42(5):404-11.

29. Pinar Erdem A, Sepet E, Kulekci G, Trosola SC, Guven Y. Effects of two fluoride varnishes and one fluoride/chlorhexidine varnish on Streptococcus mutans and Streptococcus sobrinus biofilm formation in vitro. Int J Med Sci. 2012;9(2):129-36.

30. $\mathrm{Hu} \mathrm{CH}, \mathrm{He}$ J, Eckert R, Wu XY, Li LN, Tian Y, et al. Development and evaluation of a safe and effective sugar-free herbal lollipop that kills cavitycausing bacteria. Int J Oral Sci. 2011;3(1):13-20. 